\title{
AHP Analysis of Cross-Cultural Friction and Synergy in Korean Subsidiaries of Austrian Companies
}

\author{
Sabine Schatzer and Jung Ho Kim
}

\begin{abstract}
Academic research regarding cross-cultural management has gained fundamental importance in today's globalised business world. Within this field, this paper examines cultural synergy and friction of Austrian and Korean business culture. Austrian companies have a high export orientation and have shown strong interest in doing business with Korea, which has been identified as an exceptionally attractive location for subsidiaries of foreign MNEs. Applying the Analytical Hierarchy Process, Korean employees in Korean subsidiaries of Austrian companies were surveyed regarding their satisfaction levels in different job aspects as well as their preferences regarding alternatives in the criteria leadership style, work teams, and tasks and responsibilities. The study found synergy between the preferences of Korean employees and Austrian management in the importance placed on challenging projects and chances for personal achievements at work, as well as the lack of desire for close personal relations with superiors and colleagues. The latter represents a unique finding, contrary to what had been suggested by the relevant literature. Additionally, the research found areas of cultural friction regarding the importance assigned to consultative decision-making, a relaxed use of time, and freedom when performing work tasks. Overall good satisfaction levels of Korean employees in the subsidiaries were reported.
\end{abstract}

Keywords: cross-cultural management; employee satisfaction; Korean business culture; Austrian management style; AHP

Schatzer, Sabine and Jung Ho Kim. 2018. "AHP Analysis of Sciendo Cross-Cultural Friction and Synergy in Korean Subsidiaries of Austrian Companies." Vienna Journal of East Asian Studies, 10, pp. 107-136. https://doi.org/10.2478/vjeas-2018-0005 


\section{Introduction}

The globalising business world has fundamentally influenced cross-cultural management research, becoming a catalyst for academia in this field (Soderberg and Holden 2002: 109). Today's globalisation can be defined as "an accelerating set of processes involving flows that encompass ever-greater numbers of the world's spaces and that lead to increasing integration and interconnectivity among those spaces" (Ritzer 2007: 1). One main driver of this increasingly interconnected world has been the economic sphere through foreign trade, foreign direct investment, and foreign portfolio investment (Babones 2007: 146). The growing economic globalisation has led to the emergence of multinational enterprises (MNEs). With these firms setting up subsidiaries abroad, the encounter of people with different cultural backgrounds within the business arena has become a prevailing setting for many employees. In this setting concepts such as global leadership, ${ }^{1}$ cross-cultural communication, and cultural sensitivity have been identified as crucial for successful business performance (Moran et al. 2007: 29-30). While cultural differences can easily cause friction, there is also the opportunity to create synergy, building on differences in order to accomplish growth through cooperation by emphasising similarities, integrating differences, seeking input from all parties involved, and developing cultural skills (ibid.: 30 ). To achieve synergy, global businesses need to be skilled in handling cross-cultural conflict (ibid.: 232). This paper therefore argues that a mutual understanding of respective business cultures is essential for beneficial cross-cultural performance of subsidiaries, making research in the field of cross-cultural management vital in an economically interconnected world. ${ }^{2}$

A large number of cross-national empirical studies applied the frameworks and cultural dimensions for assessing cultures, that were previously developed by scholars such as Hofstede, Trompensaars, and Hall, in order to gain understanding of selected national business cultures. These studies not only helped to validate these dimensions for academia, but also provided insights for the daily business of MNEs themselves. However, as far as the research for this paper has revealed, no studies debated subsidiaries of Austrian companies specifically.

Despite the country's smaller size, its geographical location as well as research \& development $(R \& D)$ policies are providing an attractive setting for the foundation of new companies, many quickly recognising a need to expand beyond the country's borders. According to Austria's official trade promotion organisation ADVANTAGE AUSTRIA, the country's R\&D expenditure has exceeded three per cent of its gross domestic product (GDP) in 2015, ranking the country fifth within the European Union (EU) in terms of research spending in relation to GDP (Ad-

\footnotetext{
${ }^{1}$ Defined as the ability to effectively operate in such an environment by Moran et al. 2007: 29 .

${ }^{2}$ This paper is a substantially revised version of Schatzer 2018.
} 
vantage Austria 2015). In absolute numbers, the country invested around ten billion Euros in 2015 with the highest rate of growth in the business enterprise sector (Austrian Research and Technology Report 2015: 7). In 2016, the country's spending further increased by 2.9 per cent, marking the third highest R\&D quote within the EU overtaking Germany and Denmark (Austrian Embassy Washington 2016). The Financial Times additionally attested to the country boosting an attractive startup scene, but also identified the need for the country's industry to build its competitiveness (Anderson 2015).

Many Austrian start-ups are founded as born-globals (Advantage Austria 2016). A study by Holzmüller and Kasper (1990: 217-225) on the foreign orientation of Austrian managers revealed its importance for the export success of small and medium-sized companies, as it facilitated the identification of firms with export potential. ${ }^{3}$ Their sample included 110 companies from the private sector, most employing between fifty and 1,000 people. The ninety-two respondents had an average export ratio of 33.1 per cent, with only 7.6 per cent considered home market-oriented, and 33.7 per cent being either exporters or heavy exporters with a ratio of up to and over sixty per cent, respectively (ibid.: 219-226). It can thus be concluded that doing business across borders is an integral part for Austrian companies.

The explosive economic growth of South Korea (henceforth, Korea) since 1962 has attracted a large number of MNEs, with especially American and Japanese companies investing in Korean subsidiaries (Chang and Taylor 1999). According to Korea's Financial Supervisory Service, foreign stock purchases saw another boost at the beginning of 2017 (Asia Asset Management 2017). The country has been ranked number one in the Bloomberg Innovation Index, measuring categories such as R\&D, manufacturing, high-tech companies, post-secondary education, research personnel, and patents. Regarding single categories, Korea topped R\&D as well as the one assessing post-secondary education, due to its highly educated workforce (Bloomberg 2015). The above underline Korea's attractiveness as a location for subsidiaries of foreign multinationals. However, literature has identified that Korean employees often face challenges in foreign firms that stem from cultural characteristics (Park et al. 1996: 80).

This paper therefore analyses cultural challenges and synergies regarding Korean subsidiaries of Austrian companies. First, prior literature has been reviewed based on the following questions: How does literature characterise Austrian and Korean management? How does literature characterise preferences of Korean and Austrian employees? Additionally, fundamental models for assessing cultures were applied to Austria and Korea. The combined findings allowed the development of hypotheses regarding the perceptions of Austrian management by Korean employees in respec-

\footnotetext{
399.7 per cent of all Austrian companies are SMEs, making them the most important form of business in the national market (Austrian Ministry for Science, Research, and Economy 2016).
} 
tive subsidiaries. In a following step, an empirical study was conducted in the form of a survey handed out to Koreans working for Austrian companies in Korea, designed to test the developed hypotheses. Finally, the findings of these interviews were analysed and implications were deducted.

\section{Literature Review: Cross-Cultural Management}

Cross-cultural management has been defined as "the study of the behaviour of people in organizations located in cultures and nations around the world" (Adler 1983: 226). Cross-cultural management research therefore describes organisational behaviour within countries and cultures, compares it across them, and focuses on the interaction of people from different countries working in the same company or work environment (ibid.: 226). Since its introduction, cross-cultural research has mostly been dealing with three areas: motivational theories, leadership styles, and management by objectives (Morden 1995: 16). Different cultures allowed for different conceptualisation of these terms. Therefore, the developed theories can only be considered valid for the cultural environment from which they originate. In relation to this, empirical evidence suggests that Western and Eastern traditions provide alternative views on motivation and, thus, employee satisfaction (Kao and Sek-Hong 1997: 120). Research also showed that cultural differences effect performance and that necessary incentives and general organisational forms need to differ according to local business cultures (Griswold 2008: 135).

Reflecting on this, increasing the cultural awareness of the people involved is considered to be the initial step to effective cross-cultural management (Moran et al. 2007: 25). Ideally, cultural awareness enables the creation of synergy. Adler (2002: 116) defines cultural synergy

as an approach to managing the impact of cultural diversity, involving a process in which managers form organizational policies, strategies, structures, and practices based on, but not limited to, the cultural patterns of individual organizational members and clients [...]. This approach recognizes both the similarities and differences among the cultures that compose a global organization and suggest that we neither ignore nor minimize cultural diversity, but rather view it as a resource in designing and developing organizational systems.

MNEs are operating in multicultural environments that involve several cultural groups and thus multiple systems of creating meaning (Griswold 2008: 139). Managers can anticipate how these differing meaning-creating systems can challenge operational goals and generate an organisational culture that encourages the desired behaviour by making it meaningful and satisfying (ibid.: 139-40). In return, such an organisation culture supports the reaching of organisational goals (ibid.: 135-136). Therefore, this paper's examination of Korean employees in subsidiaries of Austrian 
companies aims to uncover the synergies between the different business cultures that can contribute to employee satisfaction and motivation and thus to organisational performance overall.

In order to achieve this goal, first the involved national cultures had to be analysed. A number of widely accepted models and theories of cultural dimensions were reviewed to form the basis for this objective. This included Hofstede's (2001: 41) five cultural dimensions (power distance, uncertainty avoidance, individualismcollectivism, masculinity-femininity, and long-term versus short-term orientation) one of the most impactful models for cultural factors. Additionally, the findings of the GLOBE ("Global Leadership and Organizational Behavior Effectiveness") framework for assessing cultures were considered, including the cultural factors and leadership behaviours and attributes defined within the project (House et al. 2004: 13-14). Further consideration was given to the research of Edward T. Hall regarding high and low context, monochromic and polychromic time, as well as people's need for space (Hall 1976: 91; 313; 115). Finally, Trompensaars' (1993: 10-11) model of national cultural difference, as well as Triandis' (1995: 2; also Triandis and Suh 2002: 145-147) work focusing on individualism versus communitarianism and the cognitive structures of idiocentrism and allocentrism to relate culture and personality should be mentioned.

With regards to methodological choices, the reviewed literature revealed that many large, long-term studies in the realm of cross-cultural management have utilised classic quantitative, statistical methods (e.g., Hofstede 2001; House et al. 2004). This methodology obviously relies on significant sample sizes of a large available population. Other, less extensive studies, are sometimes completely focused on the review of secondary data (e.g., Chang and Taylor 1999; Dong and Liu 2010), thus requiring the availability of suitable samples beforehand. Finally, a number of researchers selected a qualitative approach by conducting individual interviews (e.g., Peterson et al. 2000), therefore producing more narrow findings due to very small sample sizes caused by limited resources and a strong reliance on the researcher's own interpretation. The reviewed literature did not reveal any study in the discipline of cross-cultural management that utilised the Analytical Hierarchy Process (AHP), a methodology combining the merits of quantitative and qualitative approaches. Its characteristic of focusing on the point of view of the respondent, while allowing relevant deductions for smaller sample sizes, would suggest that this method represents a suitable choice for a considerable fraction of cross-cultural management research. The lack of studies applying the AHP thus has to be noted. 


\section{Research Questions}

As the models and theories regarding cultural factors suggest, a difference between respective national business cultures can be expected. Based on this conclusion and the previously highlighted relevance of exploring the synergies and friction that Austrian companies could face in Korea, the aim of this paper is an exploration of the following research questions:

- How satisfied are Korean employees of Korean subsidiaries of Austrian companies, and what role do predicted cultural differences play for their satisfaction levels?

- Can consequences be drawn from the findings for the Austrian management of Korean subsidiaries?

As a basis for the empirical study, previous country-specific academic work was reviewed to understand the Korean and Austrian business cultures, respectively. This analysis led to a derivation of hypotheses, forming the framework for the original study. The analysis focused on main criteria that bear witness to cultural friction and synergy: leadership style, team dynamics, and tasks and responsibilities. In a following step, the derived hypotheses were tested by conducting interviews with employees in Korean subsidiaries of Austrian companies. The empirical research combined with the theoretical findings finally allowed to analyse the posed research questions. Final results, thus, provide a basis for enhancing employee satisfaction and, in return, aim to help increasing performance and organisational output.

\section{Country Analysis and Hypothesis Development: South Korea and Austria}

\section{Superior's Leadership Style}

According to Hofstede, Austria and Korea differ significantly in the cultural dimension 'Power Distance,' with Korea's absolute score being sixty, while Austria had the lowest results of all observed countries, scoring only eleven points. This indicates that Austrian managers expect limited dependence of their subordinates and exercise a pragmatic relationship style. Korean employees, however, prefer being more dependent on their boss, having an emotional relationship with their superior. This is also in line with the findings of previous studies focusing on Korea's NeoConfucian heritage, which suggest that Korean subordinates accept hierarchical inequalities more easily in exchange for a dependable leader (Hofstede et al. 2010: 
61; Hofstede 2001: 107-108; Hong et al. 2016: 344-346; 355; Kee 2008: 6-8; 11-12; Lee 2012: 189).

With regards to the closeness of interpersonal relations between superiors and subordinates, it has further been observed that Korean employees often expect a family-like work environment in exchange for their dedication to a paternalistic leader (Kee 2008: 6-8). In contrast, Markowitsch et al. (2002) noted that Austrians emphasised content training and that they lacked communication and empathy skill development, as well as emotional intelligence. According to the authors, Austrian managers need to become more involved with staff development issues (ibid.: 24), suggesting an overall rather low level of closeness with their subordinates.

Additionally, the GLOBE study stated that Austrians highly value participative leadership while Koreans consider this leadership quality as not having any impact on success. This suggests that Austrian managers involve subordinates in making and implementing decisions to a high degree (House et al. 2004: 14). However, previous studies reported that Korean employees are used to highly centralised decision-making and concentrated authority at the senior level and thus feel most comfortable with superiors who assign tasks, specify all work aspects, give detailed instructions, and provide structure (Hong et al. 2016: 344-346; Kee 2008: 6-8). Thus, high-involvement strategies are difficult to implement as Korean employees are used to a hierarchical work culture (Bae and Lawler 2000: 503).

Finally, Korean business communication has been described as that of a highcontext culture (Thomas 1998: 20-21). An emphasis on group harmony based on Confucian roots has led to Koreans avoiding to give negative information outrightinstead, delivering it later and ambiguously (Lee 2012: 186). Due to this ambiguity, foreign managers perceive to face more problems regarding internal communication than their Korean colleagues (Park et al. 1996: 84). In contrast, Austrian business communication emphasises transparency and a clear flow of information as managers feel a need to avoid uncertainty, thus informing all employees of company matters to raise the feeling of security (Papalexandris and Panayotopoulou 2004: 504).

In conclusion, it can be said that by looking at the different aspects of managerial practices, a number of differences in Korean and Austrian leadership styles have been observed. Possible issue areas between the two countries based on previous literature thus include preferences regarding the closeness of interpersonal relations with their superior and how strong and dependable they are as leaders. Additionally, decision-making processes seem to differ, as do the levels of emphasis on clear and transparent communication. Regarding leadership style, therefore, a number of hypotheses were derived:

Hypothesis 1: Korean employees are not satisfied with Austrian leadership style. 


\section{Relationship with Team Members}

Confucian ideals have been considered to be the basis for group solidarity in Korean organisations helping the minimisation of conflict (Lam 2003: 158) and can thus be concluded to be highly influential on Korean team dynamics overall. Korea scored very low on Hofstede's Individualism Index, making it a collectivist culture (Hofstede 2001: 215). This suggests that an emphasis on belonging plays an important role in work settings (ibid.: 227).

High-involvement human resource management strategies would be easily accepted due to Korea being a hierarchical culture (Bae and Lawler 2000: 503). With relation to hierarchies, culture-based roots for challenges faced by Korean employees in teams of foreign firms have been identified and included the Korean emphasis on class and rank, authoritarian hierarchy, and intricate networks of personal connections. Koreans often prefer indirect ways to communicate and tolerate ambiguity due to the importance placed on saving face, which can also be a cause for misunderstanding (Park et al. 1996: 80-83). The importance of group relationships for business leads to distrust those outside of the group, which additionally makes business more time-consuming (Oh 1991: 53). Forming deals usually takes longer as first a relationship has to be established (Lee 2012: 189). These distinct cultural aspects can lead to parent companies perceiving work hours being too relaxed and not used efficiently, resulting in unfair performance evaluations (Park et al. 1996: 88-89).

Austrian teams overall appear to be flatter than Korean work groups. Austria's middle management experiences low inequalities in power and encourages collective activity. Austrians further have a high respect towards deadlines and a preference for clear schedules and working on one task at a time (Tompos 2015: 6-10). While collectivism, group harmony, and strong team spirit characterise the work culture in Korea, with individualist intentions being considered selfish (Kee 2008: 68), Austrians in contrast have been characterised as rather individualistic, formal, and achievement-oriented (Tompos 2015: 6-10).

Overall, it can therefore be concluded that the discrepancies in team dynamics of Korean and Austrian business culture - similarly to their differing leadership styles - set the ground for possible conflict areas. The cultures show differences in the hierarchical structure of teams, their use of time, the importance of close personal relationships with colleagues, and the perceived necessity of deep integration into a work team. Based on the analysis, Koreans place exceptional importance on group relationships, whereas Austrians have been characterised as leaning towards individualism (Hofstede 2001: 215; Tompos 2015: 6). According to Triandis and Suh's (2002: 145-147) theory of fit regarding individual cognitive structures, allocentrics experience a better fit in collectivist cultures. Therefore, Austrian management 
needs a better understanding about the importance placed on team dynamics in their Korean subsidiaries. For this reason, a second hypothesis was tested.

Hypothesis 2: A good relationship with team members ranks highest for job satisfaction of Korean employees at the subsidiaries.

\section{Tasks and Responsibilities}

Austrians are said to value personal achievement through challenging projects, while such individual intentions can be considered selfish in Korean work culture due to the importance of group harmony (Tompos 2015: 6-10; Kee 2008: 12). Additionally, the degree of freedom for task performance provided by Austrian management might not be in accordance with Koreans' preference for detailed instructions and clear structure (Hong et al. 2016: 344-345). As noted previously, high-involvement human resource management strategies are difficult to implement in Korea due to its hierarchical culture (Bae and Lawler 2000: 503). It can thus be suspected that Koreans weigh challenging projects, opportunities for achievement, and a high degree of freedom as less important than their Austrian counterparts.

Overall, Austria's and Korea's differences with regards to the importance of personal relationships vis-à-vis achievement-orientation, as well as their preferred degree of freedom when performing tasks, might also lead to a difference in importance given to the actual work that is performed. The alignment of projects with personal interests may play a different role in those two business cultures-however, as far as the literature review has revealed, this field has not yet been studied. Overall, due to the analysed difference in preferences when it comes to tasks and responsibilities, a third hypothesis for these criteria was formulated:

Hypothesis 3: Korean employees are not satisfied with their tasks and responsibilities at the Korean subsidiaries of Austrian companies.

In summary, substantial discrepancies in the leadership style of Austrian and Korean businesses have been identified, including the closeness of relationships with superiors, their dependability, decision-making types, and communication styles. Similarly, team dynamics between the two countries seem to differ in areas such as hierarchical structures, use of time, importance of personal relationships, and preferred level of integration. Finally, there appear to be differences in the performance of tasks and responsibilities regarding the desired level of achievement-orientation and degree of freedom, as well as the assigned importance to challenges and personal interests. These anticipated differences between Korean and Austrian work culture, based on a country analysis, formed the basis for the original survey conducted in the form of an AHP. 


\section{Methodology: AHP}

As noted in the literature review, cross-cultural management studies tend to utilise classic quantitative statistical methods (e.g., Hofstede 2001; House et al. 2004), which require a large number of available data sets. Others only review secondary data (e.g., Chang and Taylor 1999; Dong and Liu 2010) or conduct a small number of interviews, choosing a qualitative approach (e.g., Peterson et al. 2000). Often, such methodology produces limited new findings, relying to a large extend on the personal interpretation of the researcher.

However, AHP allows for the combination of the merits and makes up for the shortcomings of other approaches by focusing on the point of view of the respondent, while allowing relevant deductions even for smaller sample sizes. As the research did not reveal any significant study in the realm of cross-cultural management academia based on AHP, applying a new methodology in this field further adds value to current research and enables a new perspective on business culture, enriching the already existing but more broad findings of previously conducted crosscultural studies. Therefore, a brief introduction of the methodology shall follow.

AHP was developed by Thomas L. Saaty as a methodology to enable making complex decisions. It has since been used for choice, prioritisation/evaluation, and forecasting in fields such as business, government, social studies, and other domains (Bhushan and Rai 2004: 15). Consistency is a major concern for AHP. According to Saaty (2008a: 83), AHP represents

a theory of measurement through pairwise comparisons and relies on the judgements of experts to drive priority scales. [...] The comparisons are made using a scale of absolute judgements that represents, how much more, one element dominates another with respect to a given attribute. [...] The derived priority scales are synthesized by multiplying them by the priority of their parent nodes and adding for all such nodes.

AHP involves the following steps (Bhushan and Rai 2004: 16-17; Saaty 2008a: 85; Saaty 2008b: 257):

1. First, the definition of the kind of knowledge that is sought, the issue area, or the problem.

2. The topic is then decomposed into a hierarchy of goals, criteria, sub-criteria, and alternatives, with the hierarchy indicating the relationship between the elements, all of which being connected to one another.

3. A set of pairwise comparison matrices is constructed with each element in upper levels used for the comparison of elements in levels immediately below with respect to it.

4. Data are collected by letting experts evaluate pairwise alternatives on a qualitative scale. The alternatives can be rated from being of equal importance (1) to having extreme importance (for example 5 or $1 / 5$, depending which of the 
two alternatives is considered extremely important), with increasing levels of importance in between the two poles, including weak, moderate, strong, and very strong.

5. The obtained comparisons from the experts are used to weigh the priorities of all elements according to their hierarchy. Corresponding relative levels of importance are calculated resulting in weighted values for all alternatives.

6. The consistency of the answers is evaluated by calculating a consistency index.

As AHP allows for the prioritisation and evaluation of options resulting in the determination of relative merits for sets of alternatives, the methodology represents the ideal tool to collect expert data necessary for exploring cultural synergies and challenges. Since research in this field naturally must always be based on personal perceptions of individuals, the methodology usefully allows for the quantification of subjective opinion.

\section{Research Design}

By selecting AHP as a methodology, a hierarchy model must form the basis for collecting the required data. As such, in a first step, the overall goal of the research was formulated: "Enhancing Employee Satisfaction in Korean Subsidiaries of Austrian Companies." By collecting data in relation to possible issues in subsidiaries, areas of cultural friction can be identified, allowing to address these issues and consequently improve the overall satisfaction of employees in the local Korean offices. This objective therefore forms level A1 in the hierarchy model.

Level B consists of the criteria to achieve the defined goal. Based on the previous analysis, three main areas contribute to the overall satisfaction of employees: "Leadership Style of Superior"; "Relationship with Team Members"; and "Tasks and Responsibilities." In the hierarchy tree, these three main criteria therefore represent $\mathrm{B} 1, \mathrm{~B} 2$, and $\mathrm{B} 3$, respectively.

Finally, each of the criteria has several alternatives or sub-criteria that comprise level $\mathrm{C}$ of the hierarchy model. Alternatives $\mathrm{C} 1$ to $\mathrm{C} 4$ are sub-criteria of criteria B1 "Leadership Style of Superior": "Closeness of Interpersonal Relations"; "Dependability as a Leader"; "Consultative Decision-Making"; and "Clearness of Overall Communication." For criteria B2 "Relationship with Team Members," the subcriteria C5 to C8 have been defined: "Clear Hierarchical Structure"; "Relaxed Use of Time"; "Friendly Relationship with Colleagues Outside of Work"; and "Deep Level of Integration." The third criteria B3, "Tasks and Responsibilities," features again four alternatives (C9 to C12): "Alignment with Interests"; Challenging Projects"; "Opportunities for Achievements"; and "Degree of Freedom." The complete hierarchy model is depicted in Figure 1. 
[Figure 1] Hierarchy Model for Key Factors of Employee Satisfaction in Korean Subsidiaries of Austrian Companies

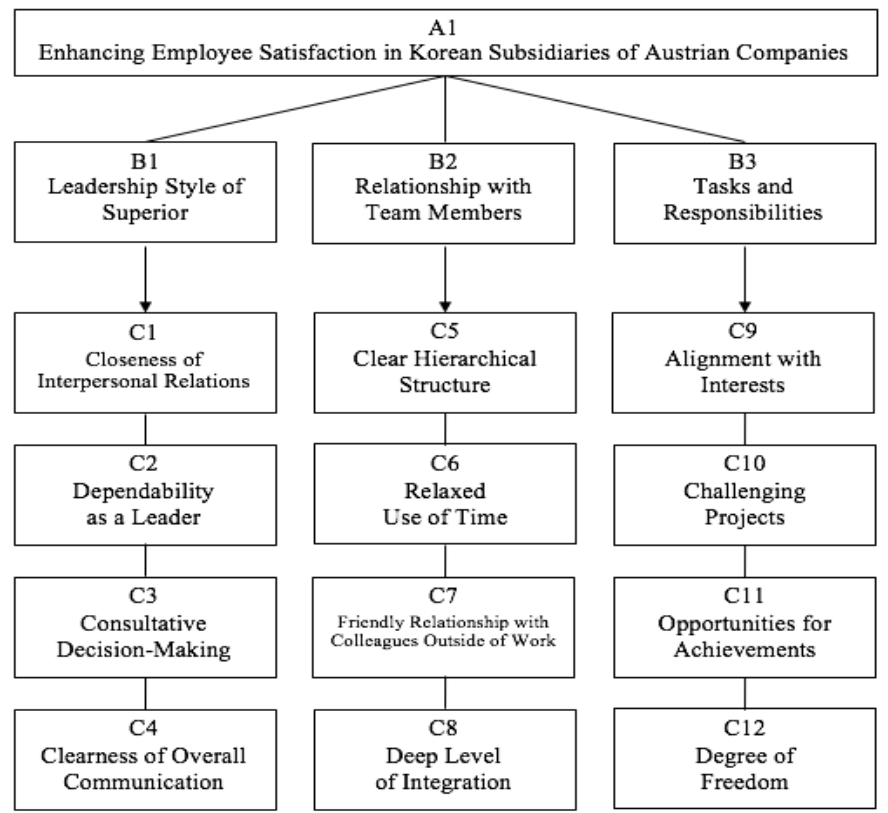

To sum up the goal of the research, in order to achieve the objective A1, "Enhancing Employee Satisfaction in Korean Subsidiaries of Austrian Companies," the importance placed on the three criteria B1-B3 (Leadership Style of Superior; Relationship with Team Members; Tasks and Responsibilities) were surveyed. The weight given to alternatives $\mathrm{C} 1-\mathrm{C} 12$ by the interviewed subject group revealed which subcriteria were considered most important within their respective main criteria (see Table 1 for the intensity of importance of the chosen weights). In addition, based on the weight of the main criterion, the relative weight of each sub-criterion was calculated. This revealed the areas most important to address when achieving the objective of increased employee satisfaction. 
[Table 1] AHP Scale

\begin{tabular}{|c|c|}
\hline Intensity of Importance & Definition \\
\hline 1 & Equal importance \\
\hline 2 & Moderate importance \\
\hline 3 & Strong importance \\
\hline 4 & Very strong importance \\
\hline 5 & Extreme importance \\
\hline
\end{tabular}

In order to calculate the average importance of all criteria and alternatives the data was entered into an AHP excel template ${ }^{4}$ which first checked for the inconsistency of each data set. The sheet computed the eigenvalue $\lambda \max$ which - together with the number of compared elements $n$-was needed to calculate the consistency of the preferences indicated by the participant. For this purpose, first the consistency index (CI) was determined. By dividing the $\mathrm{CI}$ by a given random index (RI), the consistency ratio (CR) was calculated. The formulas used by the template have been developed by Saaty (2003: 240-243; Sahin et al. 2013: 287-290):

$$
\begin{aligned}
& \mathrm{CI}=(\lambda \max -\mathrm{n}) /(\mathrm{n}-1) \\
& \mathrm{CR}=\mathrm{CI} / \mathrm{RI}
\end{aligned}
$$

The calculated CR formed the decision criterion for determining whether the data set was consistent enough to be used in the study. Usually, less than ten per cent inconsistency and thus a CR of 0.1 or lower is acceptable. However, it has been argued that in social sciences, due to the unfamiliarity of participants with the AHP method as well as the ambiguity of constructs that are compared, the consistency of the respondents can be compromised to a certain degree. The second aspect is particularly true for the sub-criteria of this survey, since, for example, the understanding of what "Closeness of Interpersonal Relations" constitutes can differ significantly between participants. Additionally, inconsistencies are also likely to occur in cases where the weights assigned to the different options are close to one another. Thus, a CR of up to 0.2 can be considered to be tolerable in such cases and was applied for this research (Kim and Kim 2016: 149; Saaty 1983: 142-143). The data sets that passed the consistency test were then used to calculate the overall results.

\footnotetext{
${ }^{4}$ Source: Business Performance Management 2017.
} 


\section{Data Collection Process}

A questionnaire was created in order to collect data. In the survey, Korean interviewees working in Korean subsidiaries of Austrian companies were asked to indicate their overall satisfaction in the three criteria of the hierarchy model on a sevenpoint scale, ranging from "very dissatisfied" to "very satisfied." After surveying the satisfaction, the questionnaire asked participants to pairwise weigh the relative importance of the criteria B1, B2, and B3 against each other. Finally, interviewees had to weigh the alternatives of the same criteria in pairs. This means that participants were asked to compare alternatives $\mathrm{C} 1$ to $\mathrm{C} 4, \mathrm{C} 5$ to $\mathrm{C} 8$, and $\mathrm{C} 9$ to $\mathrm{C} 12$, respectively, and to assign weights within each pairwise comparison. To complement the collected expert data, additional questions regarding the participants' age, years with their current company, and their work department were included.

As a first step in the collection process, Austrian companies with branch offices in Korea were researched. This was done through online research, a review of all Austrian companies on the stock market, as well as by contacting the Austrian Foreign Trade Centre in Seoul. In the end, a total number of eleven companies had been identified with purely Austrian-owned subsidiaries in Korea that were directly under Austrian management. Their respective industries included food processing, heavy metals, textile, high tech, and medical - therefore, the sample was not skewed towards a certain sector. Most companies had local sales representative offices, while a few operated production facilities, distribution offices, or service branches in Korea.

After the identification process, all companies were contacted via e-mail, both their head offices in Austria as well as their local contacts in Korea. The e-mail contact was followed up by phone calls to explain the research objective ${ }^{5}$ and the AHP methodology. The questionnaire was distributed via a link to an online survey and was available in both English and Korean to all contacted companies.

The data collection process was done over the course of summer 2017 and took two months in total. Out of the contacted companies, two branches were unable to participate. The remaining nine companies mostly had a small number of employees in Korea, ranging between one to five people. One of the participants had a slightly larger team on site. Overall, the data collection yielded twenty-three completed questionnaires, while six incomplete surveys had to be omitted. After applying the consistency test, eleven data sets passed the required CR and formed the basis for the results. It should be noted that all suitable companies for the conducted research had been contacted during data collection. Since only a small number of Korean subsidiaries of Austrian companies in total existed at the time of the research, even lower numbers of valid questionnaires could be considered as representative as they

\footnotetext{
${ }^{5}$ It was discussed that the questions should be answered with regards to the perception of the Austrian management, and by Korean employees who directly interact with Austrian superiors.
} 
comprised a considerable percentage of the total population. Additionally, the relevance was further given by the results exclusively representing expert data (Sahin et al. 2013: 292).

\section{Survey Results: Satisfaction Levels and Priorities of (Sub-)Criteria}

The survey participants were Korean employees working in Korean subsidiaries of Austrian companies. More than half of them were between thirty and thirty-nine years old ( 54.5 per cent). 36.4 percent were between the ages of forty and forty-nine, with the remaining 9.1 per cent being between twenty and twenty-nine years old. Regarding the number of years they had spent with the company, over half of them had been working for their current Austrian employer for more than seven years. Only one participant had been less than a year with the subsidiary. The departments of the interviewees included R\&D (18.2 per cent), Human Resources (36.4 per cent), Accounting \& Finance (27.3 per cent), and Administration (9.1 per cent). One participant indicated to be working in a non-specified field.

Out of the three surveyed aspects, the participating employees were most satisfied with the relationship with their team members; 81.82 per cent were either satisfied or very satisfied with this criterion. With regards to tasks and responsibilities, the satisfaction levels were slightly below that of the previous criterion, however only 18.18 per cent indicated to be dissatisfied. While the relationship with team members concerned other Korean co-workers, the criterion leadership style of superior related to Austrian management. In this work aspect, satisfaction levels were overall the lowest, with 36.36 per cent feeling either neutral or being somewhat dissatisfied to dissatisfied. (Table 2 shows the percentages of survey participants indicating each satisfaction level; options not chosen by any interviewee are left empty.) 
[Table 2] Current Satisfaction Levels of Employees at Korean Subsidiaries

\begin{tabular}{l||c|c|c}
\hline & $\begin{array}{c}\text { Leadership Style } \\
\text { of Superior }\end{array}$ & $\begin{array}{c}\text { Relationship with } \\
\text { Team Members }\end{array}$ & $\begin{array}{c}\text { Tasks and } \\
\text { Responsibilities }\end{array}$ \\
\hline Very Dissatisfied & $9.09 \%$ & & $18.18 \%$ \\
\hline Dissatisfied & $18.18 \%$ & $18.18 \%$ & \\
\hline Somewhat & $9.09 \%$ & & $9.09 \%$ \\
Dissatisfied & & & $27.27 \%$ \\
\hline Neutral & $27.27 \%$ & $54.55 \%$ & $18.18 \%$ \\
\hline Somewhat Satisfied & $36.36 \%$ & $27.27 \%$ & $27.27 \%$ \\
\hline Satisfied & & & \\
\hline Very Satisfied & & & \\
\hline
\end{tabular}

In the AHP section of the survey, the participants first had to compare the relative importance of the three main criteria for their own job satisfaction. According to the results, the interviewees ranked "Tasks and Responsibilities" as most important with a weight of 0.401 , followed by "Leadership Style of Superior" with 0.324 . "Relationship with Team Members" was considered as the least important of the three criteria for job satisfaction (0.275). It should thus be noted that the criterion ranked as least important by the participants was that with which they simultaneously indicated to be most satisfied. (The results regarding level B of the AHP section are summarised in Table 3.)

[Table 3] Weights of Criteria for Employee Satisfaction

\begin{tabular}{l|c|c}
\hline \multicolumn{1}{c|}{ Criteria } & Weights & Rank \\
\hline \hline B1 Leadership Style of Superior & 0.324 & 2 \\
\hline B2 Relationship with Team Members & 0.275 & 3 \\
\hline B3 Tasks and Responsibilities & 0.401 & 1 \\
\hline \hline CR & \multicolumn{2}{|c}{0.026} \\
\hline
\end{tabular}

$\mathrm{CR}<0.2$ 
Regarding the comparison of the sub-criteria or alternatives for "Leadership Style of Superior," "Dependability as a Leader" $(0.403)$ was locally considered most important, with a considerable lead ahead of the second ranked alternative "Clearness of Overall Communication" (0.278) and "Consultative Decision-Making" (0.203), which was ranked third. The sub-criteria "Closeness of Interpersonal Relations" was only given a local weight of 0.116 . (See Table 4 for the local weights and ranks of the alternatives.)

[Table 4] Weights of Sub-Criteria for Leadership Style of Superior

\begin{tabular}{l|c|c|c|c}
\hline \multicolumn{1}{c|}{ Sub-Criteria } & $\begin{array}{r}\text { Local } \\
\text { Weights }\end{array}$ & $\begin{array}{r}\text { Local } \\
\text { Rank }\end{array}$ & $\begin{array}{r}\text { Global } \\
\text { Weights }\end{array}$ & $\begin{array}{c}\text { Global } \\
\text { Rank }\end{array}$ \\
\hline \hline C1 Closeness of Interpersonal Relations & 0.116 & 4 & 0.038 & 12 \\
\hline C2 Dependability as a Leader & 0.403 & 1 & 0.131 & 1 \\
\hline C3 Consultative Decision-Making & 0.203 & 3 & 0.066 & 9 \\
\hline C4 Clearness of Overall Communication & 0.278 & 2 & 0.090 & 6 \\
\hline \hline CR & \multicolumn{5}{|c}{0.007} \\
\hline CR
\end{tabular}

$\mathrm{CR}<0.2$

Within the second criteria, "Relationship with Team Members," interviewees ranked "Relaxed Use of Time" (0.359) first, followed by "Clearness of Overall Communication" (0.263), and "Friendly Relationship with Colleagues Outside of Work" (0.226). The last local rank was assigned to "Clear Hierarchical Structure" with 0.152. (Table 5 shows the local weights and ranks of all sub-criteria.) 
[Table 5] Weights of Sub-Criteria for Relationship with Team Members

\begin{tabular}{l|c|c|c|c}
\hline \multicolumn{1}{c|}{ Sub-Criteria } & Local & Local & Global & Global \\
Weights & Rank & Weights & Rank \\
\hline \hline C5 Clear Hierarchical Structure & 0.152 & 4 & 0.042 & 11 \\
\hline C6 Relaxed Use of Time & 0.359 & 1 & 0.099 & 4 \\
\hline C7 Friendly Relationship with & 0.226 & 3 & 0.062 & 10 \\
Colleagues Outside of Work & & & & 7 \\
\hline C8 Clearness of Overall Communication & 0.263 & 2 & 0.072 & 7 \\
\hline \hline CR & & & & \\
\hline
\end{tabular}

$\mathrm{CR}<0.2$

The alternatives for the criterion "Tasks and Responsibilities" were overall assigned more similar local weights than the sub-criteria of the other two main criteria: "Opportunities for Achievement" received a weight of 0.297, "Challenging Projects" 0.287 , and "Alignment with Interests" 0.239. "Degree of Freedom" ranks last with 0.177. (A summary of all global ranks and weights is depicted in Table 6.)

[Table 6] Weights of Sub-Criteria for Tasks and Responsibilities

\begin{tabular}{l|c|c|c|c}
\hline \multicolumn{1}{c|}{ Sub-Criteria } & $\begin{array}{r}\text { Local } \\
\text { Weights }\end{array}$ & $\begin{array}{c}\text { Local } \\
\text { Rank }\end{array}$ & $\begin{array}{c}\text { Global } \\
\text { Weights }\end{array}$ & $\begin{array}{c}\text { Global } \\
\text { Rank }\end{array}$ \\
\hline \hline C9 Alignment with Interests & 0.239 & 3 & 0.096 & 5 \\
\hline C10 Challenging Projects & 0.287 & 2 & 0.115 & 3 \\
\hline C11 Opportunities for Achievements & 0.297 & 1 & 0.119 & 2 \\
\hline C12 Degree of Freedom & 0.177 & 4 & 0.071 & 8 \\
\hline \hline CR & \multicolumn{5}{|c}{0.005} \\
\hline
\end{tabular}

$\mathrm{CR}<0.2$

All sub-criteria have also been given a global rank and weight based on the weight of their criterion as well as their local weight. Overall, among all alternatives, the participants considered the leadership style aspect "Dependability as a Leader" most 
important with a global weight of 0.131 . The second global rank was given to "Opportunities for Achievements" regarding tasks and responsibilities with 0.119. The third highest global weight was assigned to "Challenging Projects" from the same criterion with 0.115. Among all alternatives, "A Clear Hierarchical Structure" among team members with 0.042 and "Closeness of Interpersonal Relations" with the superior with 0.038 were given the lowest global weights, and thus rank at the bottom of all sub-criteria. (Table 7 shows the ranking of all sub-criteria according to their global weight.)

[Table 7] Global Weights of Sub-Criteria for Employee Satisfaction

\begin{tabular}{|c|c|c|}
\hline $\begin{array}{l}\text { Global } \\
\text { Rank }\end{array}$ & Sub-Criteria & $\begin{array}{l}\text { Global } \\
\text { Weights }\end{array}$ \\
\hline 1 & C2 Dependability as a Leader & 0.131 \\
\hline 2 & C11 Opportunities for Achievements & 0.119 \\
\hline 3 & C10 Challenging Projects & 0.115 \\
\hline 4 & C6 Relaxed Use of Time & 0.099 \\
\hline 5 & C9 Alignment with Interests & 0.096 \\
\hline 6 & C4 Clearness of Overall Communication & 0.090 \\
\hline 7 & C8 Deep Level of Integration (Team) & 0.072 \\
\hline 8 & C12 Degree of Freedom & 0.071 \\
\hline 9 & C3 Consultative Decision-Making & 0.066 \\
\hline 10 & $\begin{array}{l}\text { C7 Friendly Relationship with Colleagues Outside of } \\
\text { Work }\end{array}$ & 0.062 \\
\hline 11 & C5 Clear Hierarchical Structure & 0.042 \\
\hline 12 & C1 Closeness of Interpersonal Relations (Superior) & 0.038 \\
\hline
\end{tabular}

$\mathrm{CR}<0.2$ 


\section{Limitations and Further Research}

The results were based on a sample size of eleven employees, which could suggest limitations regarding the relevance of the outcome. However, it should be noted again that only a small number of purely Austrian-owned subsidiaries are present in Korea as of the writing of this paper. Therefore, this sample constitutes a considerable representation, since nine out of the eleven identified companies participated in the survey. The two companies unable to contribute have Korean teams of an approximately equally small size as those who participated, thus their absence should not cause a considerable effect on the results. However, due to cooperating companies distributing the questionnaires to their employees themselves, and respondents individually deciding if they would like to fill out the survey or not, the probability of a self-selection bias has to be mentioned, which can lead to a possible overrepresentation of respondents with certain, maybe more extreme, views or experiences (Bhole and Hanna 2017: 110).

Another limitation seems to be present due to the results being based on questionnaires passing a relatively tolerant consistency ratio of 0.2 . This CR allows for a higher level of inconsistency regarding the answers of participants, which could suggest to compromise the quality of the results. However, it has previously been explained that this can be acceptable in certain research fields. Also, it should be noted that the used surveys that failed to pass the stricter consistency of 0.1 only did so with regards to one of the questions concerning the sub-criteria. Given the opportunity to individually explain the methodology to participants would possibly have allowed for the application of a stricter consistency ratio. Unfortunately, due to the limited time provided for the research by the participating companies in the private sector, this was not possible. A personal short tutorial of the methodology can be recommended for future studies.

This paper analyses the perception of Korean employees to evaluate friction and synergy between Austrian and Korean business culture. Additional studies regarding the perception of Austrian management and the experience of Austrian expat employees can be recommended to further the research in this field. Similarly, comparative research should be conducted to contrast the satisfaction of Korean employees in Austrian subsidiaries with that of Korean subordinates in similar positions working for Korean companies. Available data for this discourse focused mostly on completely different criteria or professions, thus rendering results incomparable (e.g., Kim 2015; Jung et al. 2007; Kim 2005). However, according to a 2013 survey conducted by the Samsung Economic Research Institute (2013: 10), Korean participants ranked their general work satisfaction on average fifty-three out of 100 points. This suggests a lower satisfaction level than the one found for Koreans working for subsidiaries of Austrian companies in the course of this research. A more detailed comparative study regarding the satisfaction within different aspects of work can 
thus be recommended. Additionally, research regarding the preferences and satisfaction of Koreans working in Austria for Austrian companies, as well as the perception of Austrians working for Korean companies in Austria, would allow for a more holistic view on the synergies and the possible friction areas of the two countries' respective business cultures.

Finally, exploratory research regarding the causes for the suggested higher Korean employee satisfaction in Austrian subsidiaries compared to Korean companies would allow for an understanding of how preferences might reflect a generational gap and a possible change of preferred work culture in Korea.

\section{Results: Testing of Hypotheses}

Hypothesis 1, 'Korean employees are not satisfied with Austrian leadership style,' cannot be rejected

As shown in Table 2, out of the three criteria, employees seem to be least satisfied with the leadership style of their superior. While the overall satisfaction level in the subsidiaries does not appear to be low, this criterion represents the one with the lowest percentage of respondents stating that they are at least somewhat satisfied or higher.

While the importance of the main criterion, "Leadership Style of Superior," ranks second, "Dependability as a Leader" is placed first globally among all sub-criteria. This seems to be in accordance with previous literature that suggests that Korean employees prefer a reliable leader and being dependent on their superior (Hofstede et al. 2010: 61; Hofstede 2001: 107-108; Kee 2008: 11-12; Lee 2012: 189).

Literature had also suggested that Koreans would like to have an emotional relationship with their boss, which is derived from the country's Confucian history (Kee 2008: 6-8). However, the findings of this research contradict this, as "Closeness of Interpersonal Relations" has the lowest global rank and weight of all alternatives. Literature also highlighted negative by-products of Korean familism (Sleziak 2014: 224; Yao 1999: 34), which could be a cause for the survey participants to reject traditional practices tied to filial piety towards superiors, and thus assign little importance to this sub-criterion. As previous studies pointed out, Austrian managers actually tend to be characterised by a rather low level of closeness with their staff (Markowitsch et al. 2002: 24). The lack of importance placed on a close relationship with their superior by the Korean survey participants can serve as one of the reasons why their overall satisfaction with Austrian management is higher than expected, as there seems to be less potential for cultural friction than suspected.

The weight of the sub-criterion "Consultative Decision-Making" was also rather low, placing ninth out of the twelve options. This, however, seems to be in accordance with what literature had suggested: Koreans feel comfortable with superiors 
who provide structure and specify work aspects, thus making high-involvement strategies unpopular with employees (Hong et al. 2016: 344-346; Bae and Lawler 2000: 503). As Austrian managers tend to involve their subordinates in making and implementing decisions to a high degree according to literature (House et al. 2004: 14 ), this aspect could lessen the satisfaction of Korean employees regarding "Leadership Style of Superior."

The final alternative, "Clearness of Overall Communication," was not considered important nor was it given a distinctively low weight. Literature had characterised Korea as a high-context culture (Thomas 1998: 20-21). According to Hall (1976: 91), such cultures expect more understanding without the need for explanation from their members. This might be a reason why Koreans do not feel a particularly strong desire for clear communication, although based on literature, it can be expected to be provided by Austrian management (Papalexandris and Panayotopoulou 2004: 504).

In conclusion, it can be said that most sub-criteria scored according to expectation, with the very low weight given to "Closeness of Interpersonal Relations" forming a noteworthy exception. Overall, there is evidence to suggest that Korean employees are not entirely satisfied with Austrian leadership style. Thus, Hypothesis 1 cannot be rejected.

Hypothesis 2, 'A good relationship with team members ranks highest for job satisfaction of Korean employees at the subsidiaries,' has to be rejected

Given Korea's characterisation as a collectivist culture and the role group harmony and team spirit play in Korean work culture (Hofstede 2001: 215; Kee 2008: 6-8), it had been suspected that the Korean survey participants would weigh "Relationship with Team Members" as the most important criterion for their job satisfaction. However, this option was actually ranked the lowest out of the three criteria. Notably, satisfaction levels for this work aspect were the highest and, therefore, the best satisfaction levels were achieved in the criterion that seemed to be least exposed to potential cultural friction, as the teams of the survey participants consisted of other Korean colleagues.

Out of all sub-criteria, "Relaxed Use of Time" was given the largest weight. Literature had suggested that the increased importance of relationships for business, the lengthy process necessary to establish relations, and the distrust for those outside the collective, cause business to be more time-consuming in Korea (Lee 2012: 189; Oh 1991: 53). Park et al. (1996: 88-89) reported that these distinct cultural aspects lead to parent companies perceiving work hours not to be used efficiently, being spent in a too relaxed manner. The strong importance placed on the alternative "Relaxed Use of Time" is therefore consistent with literature, and might be an indicator that Austrian management has yet to understand the necessity for allowing their employees sufficient time to conduct business successfully. 
A "Deep Level of Integration" in the team was given the second highest rank among the sub-criteria with a slightly higher weight than "Friendly Relationship with Colleagues Outside of Work." It can thus be suspected that the participants place importance on being part of the team but they do not consider relationships extending the professional setting a necessity - since "Closeness of Interpersonal Relations" with their superior has not been weighted as important.

Finally, the sub-criteria "Clear Hierarchical Structure" placed last among the four alternatives and had the second lowest global weight. While hierarchies play a large role in Korean work settings (Bae and Lawler 2000: 503; Park et al. 1996: 80-83), Korea has also been characterised as a high-context culture which expects a high level of understanding without explicit explanations (Hall 1976: 91; Thomas 1998: 20-21). The Korean survey participants therefore may take hierarchies for granted and do not require formal clarifications. Opposite to that, Austrian business culture is supposed to be characterised by a very low power distance with a preference for clear structures (Hofstede 2001: 127). Additionally, it can be presumed that Koreans often face strict hierarchies. Working for a foreign company could be seen as a chance to avoid the pressure from distinct hierarchical structures, or there might be a dislike for this cultural aspect due to personal experience.

In summary, it can be remarked that all sub-criteria, with the exception of "Relaxed Use of Time," are placed in the lower half of all alternatives, and "Relationship with Team Members" was given the lowest weight of all three criteria. Therefore, the hypothesis regarding the criterion "Relationship with Team Members" placing as most important does not hold and must be rejected.

Hypothesis 3, 'Korean employees are not satisfied with their tasks and responsibilities at the Korean subsidiaries of Austrian companies,' has to be rejected

Overall, the criterion "Tasks and Responsibilities" has been considered to be the most important option for job satisfaction by the survey participants. Satisfaction levels appear to be overall good, however 18.18 per cent indicated to be dissatisfied in that aspect, with 9.09 per cent of all interviewees were neither satisfied nor dissatisfied. As the main criterion was assigned a high weight, most of the sub-criteria also have a high global weight and rank: the locally highest-ranking alternative, "Opportunities for Achievements," was considered as second most important out of all the sub-criteria. This appears to be in parts contrary to what literature had suggested, as Korean work culture is said to consider individual intentions as selfish and place group harmony above personal goals (Kee 2008: 12). Austrians, on the other hand, have been characterised as very achievement-oriented. They are described to be preferring challenging work that allows them to achieve personal accomplishments (Tompos 2015: 6-10). The answers of the interviewed Korean employees of 
the subsidiaries of Austrian companies therefore show a high level of synergy with preferences ascribed to Austrian business practices, since "Challenging Projects" additionally ranks second locally and third globally.

The alternative "Alignment with Interests" placed third among the options of the main criterion and fifth globally. However, the weights assigned to the three mentioned sub-criteria do not differ significantly. The only sub-criterion that scored considerably less is "Degree of Freedom." This is in accordance with the previous literature review that suggested that Koreans prefer clear structures due to their familiarity with authoritative decision-styles (Hong et al. 2016: 344-345). This seems to be in accordance with their preference for a dependable leader who takes on a strong, guiding role. Since Austrian business culture is characterised by a low power distance, this appears to be an area of potential cultural friction, while the importance assigned to the other sub-criteria suggests a higher level of synergy than expected. In conclusion, Hypothesis 3 has to be rejected. Korean employees are not dissatisfied with their tasks and responsibilities at the Korean subsidiaries of Austrian companies.

\section{Discussion of Results: Implications and Recommendations}

The findings now allow for inferences regarding the research question 'How satisfied are Korean employees of Korean subsidiaries of Austrian companies and what role play predicted cultural differences?': Generally, satisfaction levels among survey participants were relatively high. For all three criteria, over half of the interviewees indicated to be satisfied or very satisfied. It shall be noted again that these results are higher than the work satisfaction levels of Koreans working under Korean management detected by the Samsung Economic Research Institute (2013: 10). It is unknown to what extent participants were maybe ranking their satisfaction higher to preserve the reputation of their company, or if they felt worried their answers could reach their employer. However, there is enough evidence suggesting that most of them are generally satisfied with their company.

Overall, the lowest satisfaction was reported with regards to "Leadership Style of Superior." The sub-criterion "Dependability as a Leader" was considered as the most important alternative for job satisfaction. It can thus be suspected that Austrian management does not appear dependable enough to the Korean survey participants. On the other hand, suspected issues regarding Austrian management often being considered as too impersonal, and Koreans preferring a close personal relationship with their superior did not hold true. With regards to "Tasks and Responsibilities," there seems to be some level of dissatisfaction as this criterion had the lowest percentage of participants ranking themselves as satisfied or very satisfied. One reason could be that Austrians prefer a higher degree freedom when performing tasks, whereas Korean interviewees ranked this alternative's importance low. 
However, overall answers regarding "Tasks and Responsibilities" correlated well with Austrian business practises. Given this surprising level of synergy, as well as the low importance placed on close personal relationships with superiors and peers, a break with the way literature had characterised Korean preferences can be observed. This could suggest a possible change in preferred work culture overall among Koreans due to a generational shift. In regards to this, it has to be remarked that Korea experienced extensive globalisation in the 1990s, after the country's rapid economic development in the previous decades. Following the Asian Financial Crisis, IMF conditions further liberalised the market (Kim and Koh 2010: 96; Koh 2010: 69; Lee et al. 2010: 139-140). These changes arguably impacted Korean business culture as well as the society, marking major shifts since the findings of Hofstede's influential research, which originated in the seventies, as well as other studies that took place already a few decades ago.

Additionally, it also has to be remarked that most of the survey participants had already been working for their Austrian employers for a number of years. This would open room for the question if working for an Austrian company has actually influenced the preferences of the Korean workers and if they have adapted to the style of their employer.

Finally, with regards to the second research question, 'Can consequences be drawn from the findings for the Austrian management of Korean subsidiaries?,' a number of recommendations can be formulated: Austrian superiors should find ways to reassure Korean employees and evoke an impression of reliability. As consultative decision-making is not particularly preferred by Korean staff, regular team alignment meetings that clearly communicate the overall goal of the company and the sub-goals of the subsidiary can help this cause, with management taking a strong leading role in these meetings, pointing out definite directions to follow and processes to achieve the defined milestones. With regards to Korean teams, Austrian management should make sure to allow employees sufficient time at work. At first, this might appear to be inefficient to Austrian businesses, but awareness should be raised that by making a more relaxed use of time possible, the performance of employees could potentially be raised, eventually leading to a better achievement of objectives. Finally, Austrian management should also provide chances for personal achievements to their Korean staff. Challenging projects and sufficient time to work on tasks can help keep the local Korean employees motivated. Clear instructions about how objectives are supposed to be achieved should be given, since a large amount of freedom for task performance might be considered intimidating and discouraging. Overall, a kick-off workshop to align Austrian management and the Korean staff by highlighting synergies and working on areas of friction can be a good starting point to increase employee satisfaction and, thus, the performance of Korean subsidiaries. 


\section{Conclusion}

This study has aimed to contribute to research in the field of cross-cultural management, since academia in this discipline has gained fundamental importance in today's globalised business world with its accelerating number of MNEs and the crucial role cultural sensitivity and global leadership take on for the performance of corporations in this setting (Moran et al. 2007: 29-30; Soderberg and Holden 2002: 109). This paper has focused on Austria as a home country due to its attractive R\&D policies, and the global as well as export orientation of Austrian companies (Austrian Embassy Washington 2016). Korea was chosen as a host country because it constitutes an exceptionally attractive location for branch offices of foreign multinationals (Bloomberg 2015). While research revealed a small number of Austrian companies that currently have subsidiaries in Korea, Advantage Austria ${ }^{6}$ lists 417 firms with business interests in Korea as of October 2017 (Advantage Austria 2017). This not only suggests a great potential of trade between the two markets, but also for a future increase of Austrian branch offices in Korea.

Therefore, this study has aimed to understand the commonalities and differences between Austrian and Korean business culture. The achievement of the original research is the detection of an unexpected amount of synergy between the preferences indicated by the Korean employees in the survey and practices by Austrian management as outlined in prior literature. As discussed, this included valuing challenging work with chances for personal achievements (Tompos 2015: 6-10) and the lack of desire for close personal relations at the work place (Markowitsch et al. 2002: 24). Other main findings are reported differences and, thus, possible areas of cultural friction: these included the high regards for a dependable leader by Korean employees versus the reportedly low power distance of Austrian work culture (Hofstede 2001: 87). Further discrepancies are found in the area of consultative decisionmaking, which Austrians prefer (House et al. 2004: 14), the Korean favouritism for a relaxed use of time at work (Park et al. 1996: 88-89), and the lack of importance placed on freedom to perform work tasks according to their own choice by Korean employees (Hofstede 2001: 107-108).

As the AHP hierarchy model depicted, the overall goal of the original study was to allow the enhancement of the satisfaction of Korean employees at Korean subsidiaries of Austrian companies. Thus, in conclusion, the findings aim to contribute to the creation of cultural synergy between the respective business cultures by examining the preferences of Korean employees in the subsidiaries. This, in return, allows to raise employee satisfaction and thus organisational performance overall, contrib-

\footnotetext{
${ }^{6}$ Advantage Austria is the online portal of the Austrian Federal Economic Chamber which represents and coordinates the interests of Austrian businesses.
} 
uting to the deepening of economic ties between the two countries and increasing the performance of Austrian multinationals.

The uniqueness of the research was not only given by the chosen countries, but also by the methodological approach and the use of the AHP. By applying a new methodology, the study's goal was also to add to cross-cultural management academia.

Finally, the outcome highlighted the necessity for further research in this field, specifically regarding the perception of Austrian management, various comparative studies, ${ }^{7}$ the degree of adjustment of Korean employees to the business culture of their employer, and possible changes in preferred work culture among younger Koreans. Given the significance of this research area in today's globalised business community, this academic field will surely continue to allow for valuable contributions.

\section{REFERENCES}

Adler, Nancy J. 1983. "Cross-Cultural Management Research: The Ostrich and the Trend." Academy of Management Review, 8 (2), pp. 226-232.

Adler, Nancy J. 2002. International Dimensions of Organizational Behavior. Fourth Edition. Cincinnati: South-Western Thomson Learning.

Advantage Austria. 2017. “Austrian Companies with Business Interests in Korea.” Online: http://www.advantageaustria.org/kr/oesterreich-in-south-korea/Buero-Seoul.en.html (accessed: October 10, 2017).

Advantage Austria. 2016. "R\&D Expenditure in Austria Continues Steady Rise." Online: http://www.advantageaustria.org/international/zentral/news/aktuell/20150507_Forschungsquot e_2015.en.html (assessed: February 24, 2017).

Advantage Austria. 2015. "Prizes for 55 Young Austrian Firms Who Have Set Their Sights on Internationalisation from Day One." Online: http://www.advantageaustria.org/ international/zentral/news/aktuell/20160708_FRESH_VIEW_Born_Global_Champions_II.en.html (accessed: February 22, 2017).

Anderson, Robert. 2015. "Austria’s R\&D Spending Has Risen But Reform Agenda Fails To Bite." Financial Times. Online: https://www.ft.com/content/ed4d1400-669a-11e5-97d01456a776a4f5 (accessed: February 21, 2017).

Asia Asset Management. 2017. "Korea's Capital Market Attractive to Foreign Investors.” Online: http://www.asiaasset.com/news/FSS_0902ch_NH_DM_final.aspx (accessed: April 28, 2017).

Austrian Embassy Washington. 2016. "Austria Achieves Third Highest R\&D Quota in EU." Austrian Press \& Information Service in the United States - Embassy of Austria. Washington, D.C. Online: http://www.austria.org/the-latest/2016/4/26/austria-achieves-third-highest-rdquota-in-eu (accessed: February 21, 2017).

Austrian Ministry for Science, Research, and Economy. 2016. "Kleine und mittlere Unternehmen in Österreich - Facts and Figures." Online: http://www.bmwfw.gv.at/Unternehmen/UnternehmensUndKMU-

\footnotetext{
${ }^{7}$ As outlined previously, this includes Koreans working for Korean companies, Koreans working in Austria for Austrian employers, and Austrians working under Korean management in Austria.
} 
Politik/Seiten/KleineundmittlereUnternehmeninOesterreich_FactsandFeatures.aspx (accessed: February 22, 2017).

Austrian Research and Technology Report. 2015. Online:

https://www.bmvit.gv.at/en/service/publications/downloads/downloads_ftb/ftb_2015_en.pdf (accessed February 21, 2017).

Babones, Salvatore. 2007. "Studying Globalization: Methodological Issues." In George Ritzer, ed., The Blackwell Companion to Globalization. Oxford: Blackwell Publishing Ltd., pp. 144-161.

Bae, Johngseok and John J. Lawler. 2000. "Organizational and HRM Strategies in Korea: Impact on Firm Performance in an Emerging Economy." Academy of Management Journal, 43 (3), pp. 502-517.

Bhole, Bharat and Bríd Hanna. 2017. "The Effectiveness of Online Reviews in the Presence of Self-Selection Bias.” Simulation Modelling Practice and Theory, 77, pp. 108-123.

Bhushan, Navneet and Kanwal Rai. 2004. Strategic Decision Making: Applying the Analytical Hierarchy Process. London and Berlin: Springer Verlag.

Bloomberg. 2015. "The Bloomberg Innovation Index.” Online: https://www.bloomberg.com/graphics/2015-innovative-countries/ (accessed: February 22, 2017).

Business Performance Management. 2017. AHP Excel Template with Multiple Inputs. Online: http://bpmsg.com/new-ahp-excel-template-with-multiple-inputs/ (assessed: August 10, 2017).

Chang, Eunmi and Susan M. Taylor. 1999. "Control in Multinational Corporations (MNCs): The Case of Korean Manufacturing Subsidiaries.” Journal of Management, 25, pp. 541-565.

Dong, Keyong and Ying Liu. 2010. "Cross-Cultural Management in China: Cross Cultural Management.” An International Journal, 17 (3), pp. 223-243.

Griswold, Wendy. 2008. Cultures and Societies in a Changing World. Third Edition. Thousand Oaks, CA: Pine Forge Press.

Hall, Edward T. 1976. Beyond Culture. New York: Anchor Books.

Hofstede, Geert. 2001. Culture's Consequences: Comparing Values, Behaviors, Institutions, and Organizations Across Nations. Second Edition. Thousand Oaks, CA: Sage Publications Inc.

Hofstede, Geert, Gert Jan Hofstede, and Michael Minkov. 2010. Cultures and Organizations: Software of the Mind. New York: McGraw-Hill.

Holzmüller, Hartmut H. and Helmut Kasper. 1990. "The Decision-Maker and Export-Activity: A Cross-National Comparison of the Foreign Orientation of Austrian Managers." Management International Review, 30, pp. 217-230.

Hong, Gahye, Youngsam Cho, Fabian Jintae Froese, and Mannsoo Shin. 2016. "The Effect of Leadership Styles, Rank, and Seniority on Affective Organizational Commitment: A Comparative Study of US and Korean Employees." Cross Cultural \& Strategic Management, 23 (2), pp. 340-362.

House, Robert J., Paul J. Hanges, Mansour Javidan, Peter W. Dorfman, and Vipin Gupta. 2004. Culture, Leadership, and Organizations: The GLOBE Study of 62 Societies. Thousand Oaks, CA: Sage Publications Inc.

Jung, Kwangho, M. Jae Moon, and Sung Deuk Hahm. 2007. "Do Age, Gender, and Section Affect Job Satisfaction? Results from the Korean Labor and Income Panel Data." Sage Journals, 27 (2), pp. 125-146.

Kao, Henry S. R. and Ng. Sek-Hong. 1997. "Work Motivation and Culture.” In Donal Munro, John F. Schumaker, and Stuart C. Carr, eds., Motivation and Culture. New York: Routledge, pp. 119-132.

Kee, Tan Soo. 2008. "Influences of Confucianism on Korean Corporate Culture." Asian Profile, $36(1)$, pp. 1-15. 
Kim, Do Hoon and Youngsun Koh. 2010. "Korea's Industrial Development.” In Il SaKong and Youngsun Koh, eds., The Korean Economy: Six Decades of Growth and Development. Seoul: Korea Development Institute, pp. 83-122.

Kim, Hyun Kim. 2015. "Moving Toward a Better Understanding of Job Satisfaction of South Korean Masseurs with Visual Impairments: Test of Integrative Job Satisfaction Model in Social Cognitive Career Theory." PhD thesis, University of Iowa, United States.

Kim, Sangmook. 2005. "Gender Differences in the Job Satisfaction of Public Employees: A Study of Seoul Metropolitan Government, Korea.” Sex Roles, 52 (9/10), pp. 667-681.

Kim, Suwon and Seongcheol Kim. 2016. "A Multi-Criteria Approach Toward Discovering Killer IoT Application Korea.” Technological Forecasting \& Social Change, 102 (1), pp. 143-155.

Koh, Youngsun. 2010. "The Growth of Korean Economy and the Role of Government." In Il SaKong and Youngsun Koh, eds., The Korean Economy: Six Decades of Growth and Development. Seoul: Korea Development Institute, pp. 7-82.

Lam, Kit-Chun Joanna. 2003. "Confucian Business Ethics and the Economy.” Journal of Business Ethnics, 43, pp. 153-162.

Lee, Choong Y. 2012. "Korean Culture and Its Influence on Business Practice in South Korea." The Journal of International Management Studies, 7 (2), pp. 184-191.

Lee, Junkyu, Jungho Yoo, Nakgyoon Choi, Jeong Gon Kim, June Dong Kim, Hae-Jung Hyun, Sangkyom Kim, Jinkyo Suh, Deok Ryong Yoon, Hongshik Lee, and Yoocheul Song. 2010. "International Economic Policy." In Il SaKong and Youngsun Koh, eds., The Korean Economy: Six Decades of Growth and Development. Seoul: Korea Development Institute, pp. 123177.

Markowitsch, Jorg, Iris Kollinger, John Warmerdam, Hans Moere, John Konrad, Catherine Burell, and David Guile. 2002. Competence and Human Resource Development in Multinational Companies in Three European Union Member States: A Comparative Analysis Between Austria, the Netherlands and the United Kingdom. Luxembourg: Office for Official Publications of the European Communities.

Moran, Robert T., Philip R. Harries, and Sarah V. Moran. 2007. Managing Cultural Differences: Global Leadership Strategies for the 21st Century. 7th edition. Oxford: Elsevier Inc.

Morden, Tony. 1995. "International Culture and Management." Management Decision, 33 (2), pp. $16-21$.

Oh, Tai K. 1991. "Understanding Managerial Values and Behaviour Among the Gang of Four: South Korea, Taiwan, Singapore and Hong Kong." Journal of Management Development, 10 (2), pp. 46-56.

Papalexandris, Nancy and Leda Panayotopoulou. 2004. "Exploring the Mutual Interaction of Societal Culture and Human Resource Management Practices: Evidence from 19 Countries." Employee Relations, 26 (5), pp. 495-509.

Park, Hoon, Sun Dai Hwang, and Kline J. Harrison. 1996. "Sources and Consequences of Communication Problems in Foreign Subsidiaries: The Case of United States Firms in South Korea." International Business Review, 5, pp. 79-98.

Peterson, Richard B., Nancy K. Napier, and Won Shul-Shim. 2000. "Expatriate Management: A Comparison of MNCs Across Four Parent Countries." International Business Review, 42 (2), pp. $145-166$.

Ritzer, George. 2007. The Blackwell Companion to Globalization. Oxford: Blackwell.

Saaty, Thomas L. 1983. "Priority Setting in Complex Problems." IEEE: Transactions on Engineering Management, 30 (3), pp. 140-155.

Saaty, Thomas L. 2003. "Why the Magic Number Seven Plus or Minus Two." Mathematical and Computer Modelling, 38 (1), pp. 233-244. 
Saaty, Thomas L. 2008a. "Decision Making with the Analytical Hierarchy Process." International Journal Services Sciences, 1 (1), pp. 83-98.

Saaty, Thomas L. 2008b. "Relative Measurement and Its Generalization in Decision Making. Why Pairwise Comparisons Are Central in Mathematics for the Measurement of Intangible Factors. The Analytical Hierarchy/Network Process." RACSAM, 102 (2), pp. 251-318.

Sahin, Oz, Sherif Mohamed, Jan Warnken, and Anisur Rahman. 2013. "Assessment of Sea-Level Rise Adaptation Options: Multiple-Criteria Decision-Making Approach Involving Stakeholders." Structural Survey, 31 (4), pp. 283-300.

Samsung Economic Research Institute. 2013. "Worker Happiness in Korea." Online: http://www.seriworld.org/01/wldContV.html?mn=B\&mncd=0101\&key=20130617000001\&se ctno $=\&$ cont_type $=\mathrm{C}$ (assessed: October 19, 2017).

Schatzer, Sabine. 2018. "Cross-Cultural Friction and Synergy: Employee Satisfaction in Korean Subsidiaries of Austrian Companies.” M.A. thesis, Korea University, South Korea.

Sleziak, Tomasz. 2014. "The Influence of Confucian Values on Modern Hierarchies and Social Communication in China and Korea: A Comparative Outline.” Kritike, 8 (2), pp. 207-232.

Soderberg, Anne-Marie and Nigel Holden. 2002. "Rethinking Cross Cultural Management in a Globalizing Business World.” International Journal of Cross Cultural Management, 2 (1), pp. $103-121$.

Thomas, Jane. 1998. “Contexting Koreans: Does the High/Low Model Work?” Business Communication Quarterly, 61 (4), pp. 9-22.

Tompos, Anikó. 2015. "Austrian and Hungarian Values and Norms in Cross-Cultural Management Research.” Impresa Progetto - Electronic Journal of Management, 12 (3), pp. 1-16.

Triandis, Harry C. 1995. Individualism and Collectivism. Boulder, CO: Westview Press.

Triandis, Harry C. and Eunkook M. Suh. 2002. "Cultural Influences on Personality." Annual Reviews Psychology, 53, pp. 133-160.

Trompensaars, Fons. 1993. Riding the Waves of Culture: Understanding Diversity in Global Business. London: The Economist Books.

Yao, Xinzhong. 1999. "Confucianism and its Modern Values: Confucian Moral, Educational and Spiritual Heritages Revisited.” Journal of Beliefs \& Values, 20 (1), pp. 30-40.

\section{ABBREVIATIONS}

AHP

CR

EU

GDP

GLOBE

IMF

MNE

R\&D

SME
Analytical Hierarchy Process

Consistency Index

European Union

Gross Domestic Product

Global Leadership and Organizational Behaviour Effectiveness

International Monetary Fund

Multinational Enterprise

Research \& Development

Small and Medium-sized Enterprise 